\title{
Molecular mechanisms of Spemann's organizer formation: conserved growth factor synergy between Xenopus and mouse
}

\author{
Tetsuro Watabe, Sam Kim, Albert Candia, Ute Rothbächer, Chikara Hashimoto, Kunio Inoue, ${ }^{1}$ and \\ Ken W.Y. Cho ${ }^{2}$ \\ Department of Developmental and Cell Biology, and Developmental Biology Center, University of California, Irvine, CA \\ 92717-2300
}

\begin{abstract}
Mesoderm induction assays in Xenopus have implicated growth factors such as activin, $\mathrm{Vg1}, \mathrm{Xwnt}-8$, and noggin as important in directing the formation of dorsal mesoderm (Spemann's organizer). Because these growth factors are structurally very different, they presumably act through distinct cell surface receptors that initiate different intracellular signaling cascades. A consequence of all of these signaling pathways, however, seems to be the induction of goosecoid (gsc) gene expression. To understand how integration of these different signaling pathways results in formation of Spemann's organizer, we sought to identify growth factorresponsive elements within the gsc promoter. Through microinjection of reporter genes we have identified two cis-acting elements, a distal element (DE) and a proximal element (PE), that are required for activin/BVg1 and Wnt induction, respectively. We have shown that the DE mediates activin induction in the absence of protein synthesis and therefore constitutes the first activin response element identified to interpret transforming growth factor- $\beta$ (TGF- $\beta$ ) superfamily member signaling directly. Using a reporter gene construct containing a multimerized DE, we find that an activin/BVg1-type signaling cascade is active throughout the vegetal hemisphere and marginal zone but not in the animal hemisphere. We demonstrate further that both the distal and proximal elements are essential for high-level transcription of the gsc gene, specifically in dorsal mesoderm, strongly suggesting that establishment of Spemann's organizer requires synergistic input from activin/BVg1-like and Wnt signaling pathways. Finally, mechanisms of establishing the organizer are likely to be conserved throughout vertebrate evolution.
\end{abstract}

[Key Words: Mesoderm; TGF- $\beta$; activin; axis specification; Vgl; goosecoid; homco box; Wnt]

Received September 8, 1995; revised version accepted October 23, 1995.

How the body axis is established during early embryogenesis is one of the fundamental questions in embryology. The most inspiring experiments in the history of the study of embryonic axis formation were those carried out by Spemann and Mangold in 1924. By transplanting a small piece of the dorsal lip of the blastopore /also called the organizer) into the lateral/flank region of another embryo, they showed that the transplanted tissue was able to change the fate of host cells in the area of the transplant, resulting in a twinned embryo /Spemann and Mangold 1924). Thus, the organizer has the capacity to initiate gastrulation movements, to convert the prospective ventral mesoderm to dorsal mesoderm, and change prospective ectoderm to neural ectoderm. Because of these unique functional capabilities of the organizer, intense efforts have been placed on deciphering its molecular properties.

\footnotetext{
${ }^{1}$ Present address: Department of Biophysics, Kyoto University, Kyoto, Japan.

${ }^{2}$ Corresponding author.
}

Just as intriguing is the question of how the organizer is established during gastrulation. The organizer is formed on the dorsal side of the gastrula embryo in the equatorial region through inductive interactions between ectoderm and endoderm. Conjugation experiments have demonstrated that vegetal endoderm explants can influence animal cap ectoderm to form mesodermal tissue (Nieuwkoop 1969). Moreover, the type of the mesoderm tissue arising from these conjugates depends on the dorsoventral (D/V) polarity of the endodermal fragments. Conjugation of animal cap ectoderm with a dorsal vegetal (endoderm) fragment, also known as the Nieuwkoop center, induces dorsal mesoderm (prospective organizer), whereas similar experiments with ventral vegetal fragments induce only ventral mesoderm (Nicuwkoop 1973; Dale and Slack 1987b). These observations have led to a hypothesis that the endoderm of amphibian embryos contains at least two different types of factors that are differentially localized: one is localized in the dorsal endoderm that is involved in the induction of the organizer, and the other is localized in the 
ventral endoderm that induces the remainder of the mesoderm. Once the organizer is induced, it is thought to release a third signal within the marginal zone to pattern the mesoderm further. This model of mesoderm induction, known as the three-signal model, has been hypothesized to explain how the $\mathrm{D} / \mathrm{V}$ patterning of mesoderm is established during early embryogenesis (Dale and Slack 1987b).

Members of the fibroblast growth factor $|F G F|$ and transforming growth factor- $\beta$ (TGF- $\beta$ ) superfamilies have been implicated as signaling molecules involved in mediating mesoderm induction (Smith 1993). Particular attention has been focused on members of the TGF- $\beta$ family, as these are thought to be involved in dorsal mesodermal signaling and, hence, in the establishment of the organizer. One leading candidate is activin, which has been shown to induce different kinds of mesodermal tissues and markers in a concentration-dependent manner in both animal cap explants (Ariizumi et al. 1991; Green et al. 1992) and in the embryo (Gurdon et al. 1994). Ectopic expression of activin in early cleavage stage Xenopus embryos leads to induction of partial secondary axes (Thomsen et al. 1990). Additionally, when activin signaling is blocked in the embryo by ectopic expression of a dominant-negative mutant of the activin type-II receptor, mesoderm formation is completely disrupted (Hemmati-Brivanlou and Melton 1992). However, the role of activin in mesoderm formation has been questioned following recent findings in mice deficient in activin or activin type-II receptor genes, in which the formation of mesoderm was not disrupted (Matzuk et al. 1995a,b). $V g 1$, another TGF- $\beta$ family member, is also a candidate molecule as a dorsal mesoderm inducer. Whereas both $V g 1$ mRNA and its protein are localized to the vegetal region of oocytes and embryos, the $\mathrm{Vg} 1$ protein detected in embryos is biologically inactive as a result of inefficient cleavage processes that fail to release a mature, active peptide (Tannahill and Melton 1989). However, when $\mathrm{Vgl}$ is processed as a bone morphogenetic protein (BMP)-Vgl chimera (BVgl), the mature Vgl peptide efficiently induces dorsal mesoderm in animal caps and can rescue UV-ventralized embryos (Thomsen and Melton 1993; Dale et al. 1993).

In addition to molecules such as activin and $\mathrm{BVgl}$ that are capable of directly inducing mesoderm on isolated naive ectoderm, there is another class of molecules with the ability to change the type of the mesoderm induced. These molecules, known as competence modifiers, include noggin (Smith and Harland 1992) and members of the Wnt family (Christian et al. 1992). Wnt members are secreted glycoproteins of the wingless/int family. Ectopic expression of synthetic Xwnt-8 RNA in the ventral portion of an early cleavage stage frog embryo leads to the formation of an additional dorsal signaling (Nieuwkoop) center, resulting in a secondary axis (Sokol et al. 1991; Smith and Harland 1991). Whereas ectopic expression of Xwnt- 8 in animal cap ectoderm through injected mRNA is ineffective as a mesoderm inducer, $X w n t-8$ appears to alter the response of ectoderm to mesoderminducing growth factors such as basic FGF (bFGF) or ac- tivin. When these growth factors alone are applied at low concentration, animal caps differentiate into ventral mesoderm. However, with the addition of Xwnt-8, ectodermal cells differentiate into dorsal mesoderm, suggesting that Xwnt- 8 modifies the response of cells to growth factors, allowing a shift to more dorsal character (Christian et al. 1992; Sokol and Melton 1992).

The discovery of these competence modifiers has led to an alternative proposal to the three-signal model. This model differs from the traditional three-signal model in that localized competence modifiers (e.g., Xwnt-8) are proposed to regulate the responsiveness of cells to the mesoderm-inducing factors, such as FGF and an activinlike molecules (Kimelman et al. 1992; Moon and Christian 1992). The competence modifiers are not able to induce mesoderm themselves but are able to work synergistically with mesoderm-inducing factors to establish patterning within the marginal mesoderm and to form mesoderm of dorsal character (Spemann's organizer).

We wished to understand the molecular mechanisms involved in the establishment of the organizer and its activities in the amphibian to better comprehend the process of vertebrate gastrulation and the formation of primary axes. To initiate such studies, previously we had isolated an organizer-specific homeo box gene, goosecoid (gsc), in Xenopus (Cho et al. 1991). Ectopic expression of gsc mRNA in the ventral side of the embryo can mimic Spemann's organizer activity by initiating gastrulation movements and inducing a secondary axis (Cho et al. 1991; Niehrs et al. 1993). Additionally, gsc was shown to be directly inducible by activin in the absence of protein synthesis (Cho et al. 1991), similar to many other genes expressed in the organizer (e.g., Xlim (Taira et al. 1992); Xbra (Smith et al. 1991)]. Therefore, we reasoned that further analysis of $g s c$ induction by growth factors such as activin/BVgl and $X w n t-8$ should provide insights into organizer formation and the regulation of gastrulation in vertebrates. It should be noted, however, that whereas activin/BVgl and Xwnt- 8 have been implicated to play important roles in organizer formation, these factors may not represent the endogenous factors in the embryo. Instead, they may mimic maternally deposited factors yet to be identified. At present, Xwnt-11 and Xwnt-8b have been shown to be maternally expressed Wnt family members (Ku and Melton 1993: Cui et al. 1995). Regardless, we decided to take advantage of the properties of activin/BVgl and Xwnt -8 to study the regulation of $g s c$ in Xenopus because they may aid in elucidating the molecular mechanisms of organizer formation.

This study describes our initial characterization of $\mathrm{Xe}$ nopus gsc gene regulation. We have identified two promoter elements, which we have named DE (distal element) and PE (proximal element), that are required for the efficient and faithful regulation of $g s c$ expression in vitro as well as in vivo. The $D E$ is the first identified cis-acting element that responds to signaling from members of the TGF- $\beta$ family. The DE responds to dorsal mesoderm signals mimicked by activin and BVgl, and the PE responds to Wnt signaling. It appears that these two sets of signals synergistically regulate the expression 
level of gsc via these elements. These results suggest that formation of the organizer also requires synergistic growth factor signaling via the DE and PE. Furthermore, we show that the DE and PE are conserved structurally and functionally between Xenopus and mouse gsc genes and propose that the regulatory mechanisms for the initiation of organizer formation and vertebrate gastrulation have been conserved during evolution at the most basic biochemical level.

\section{Results}

Identification of a cis-acting element required for activin responsiveness within the gsc promoter

A Xenopus genomic clone containing the gsc gene was cloned and mapped as shown in Figure 1A. The gene was shown to consist of three exons. Interestingly, the homeo box of the $g s c$ gene is divided into two exons 12 and 3). The gsc transcription initiation site was mapped, using both primer extension and RNase protection assays (data not shown), to a position 13 nucleotides upstream of the initiator methionine codon (Fig. 1B). A TATA-like

A

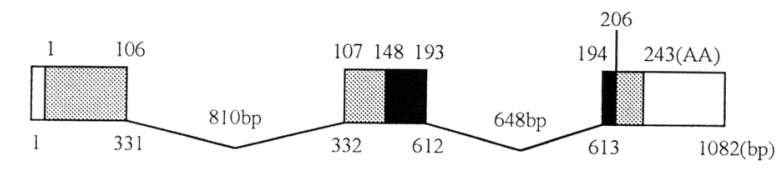

B

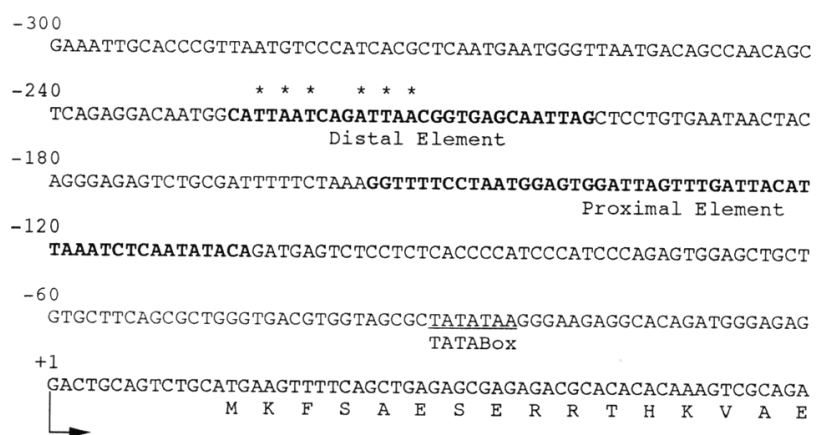

Figure 1. Genomic organization of the Xenopus gsc gene. $|A|$ gsc has three exons, with the homeo box being divided by exons 2 and 3 . Untranslated regions are in white, with black and shaded regions representing protein-coding sequences of homeo domain and non-homeo domain regions, respectively. Numbers above boxes indicate amino acids; numbers below boxes indicate the number of nucleotides in the cDNA from the transcription start site. $(B)$ Sequence of Xenopus gsc promoter. The first 60 nucleotides of exon 1 with its deduced amino acids and 300 nucleotides of 5' promoter sequence are shown. The transcription start site is indicated with an arrow, and the TATA-like sequence is underlined. The distal and proximal elements are indicated in boldface type. Mutated nucleotides in the M4gsc/ Luc reporter gene (see Fig. 2B) are indicated by asterisks. The GenBank accession number for the Xenopus gsc promoter sequence is U39291. sequence was found 30 nucleotides upstream of the transcription initiation site.

Because gsc is directly inducible by activin in the absence of protein synthesis, and activin-like activity has been implicated as important for the establishment of organizer mesoderm, we attempted to identify an activin-responsive element within the promoter of gsc. A $1.5 \cdot \mathrm{kb}$ piece of gsc 5 -flanking sequence, including $12 \mathrm{bp}$ of the 5'-untranslated leader, was subcloned into a promoterless luciferase reporter plasmid, pOLuc (de Wet et al. 1987). The resulting plasmid, $-1500 \mathrm{gsc} / \mathrm{Luc}$, was microinjected into the animal hemisphere of four-cell stage embryos (see Fig. 2A). Animal caps were dissected at the blastula stage, incubated with or without activin for $3 \mathrm{hr}$, and then prepared as extracts for luciferase assays. The level of activin induction was obtained by calculating the ratio of luciferase activity between activin-treated animal caps and untreated caps. As shown in Figure 2B, activin induces the $-1500 \mathrm{gsc} /$ Luc reporter gene 40 -fold. The induction of the reporter gene by activin is $g s c$-promoter dependent, because a pOLuc variant containing the reverse orientation of the gsc promoter was not activin inducible (data not shown). Furthermore, microinjection of other luciferase reporter gene constructs containing promoters of cy tomegalovirus (CMV) or SV40 did not respond to activin induction (data not shown).

Knowing that $-1500 \mathrm{gsc} / \mathrm{Luc}$ responded to activin signaling, we proceeded to map the $5^{\prime}$ boundary of the region within the gsc promoter required for activin induction, using a series of $5^{\prime}$ deletion constructs. Figure $2 \mathrm{~B}$ shows that deletion constructs reaching to position -226 relative to the transcription initiation site were still activin-inducible (lines 2,3). Further deletion of the gsc promoter abolished the response to activin (line 4). Because the region between -226 and -198 appeared to be essential for activin induction, point mutations were introduced within the region and tested for activin induction. We found that point mutations between -226 and $-198 \mathrm{bp}$ abolished the level of activin induction of the gsc reporter gene (Fig. 2B, line 5). This 29-bp region essential for activin induction is referred to as the DE.

\section{The DE is sufficient for direct activin induction}

To test whether the DE was sufficient for activin induction, concatenated DE was subcloned in front of a heterologous promoter [the thymidine kinase (TK) promoter of herpes simplex virus (Luckow et al. 1987)] and the gsc endogenous minimal promoter (104 bp of 5'-flanking region). Animal cap assays using reporter constructs with six copies of the DE [DE $(6 \mathrm{X}) \mathrm{TK} / \mathrm{Luc}$ and DE $(6 \mathrm{X}) 104 \mathrm{gsc} /$ Luc] revealed that the $\mathrm{DE}$ was responsive to activin, whereas the TK/Luc vector was not (Fig. 2B, lines 6-8). The increased reporter gene activity of $\mathrm{DE}(6 \mathrm{X}) \mathrm{TK} / \mathrm{Luc}$ correlated with an increase in the rate of transcription of the reporter gene, as determined by primer extension assay (Fig. 3, lanes 1 and 2). From these analyses, we conclude that the DE is not only necessary but also sufficient to respond to activin.

We next determined whether activin induction 


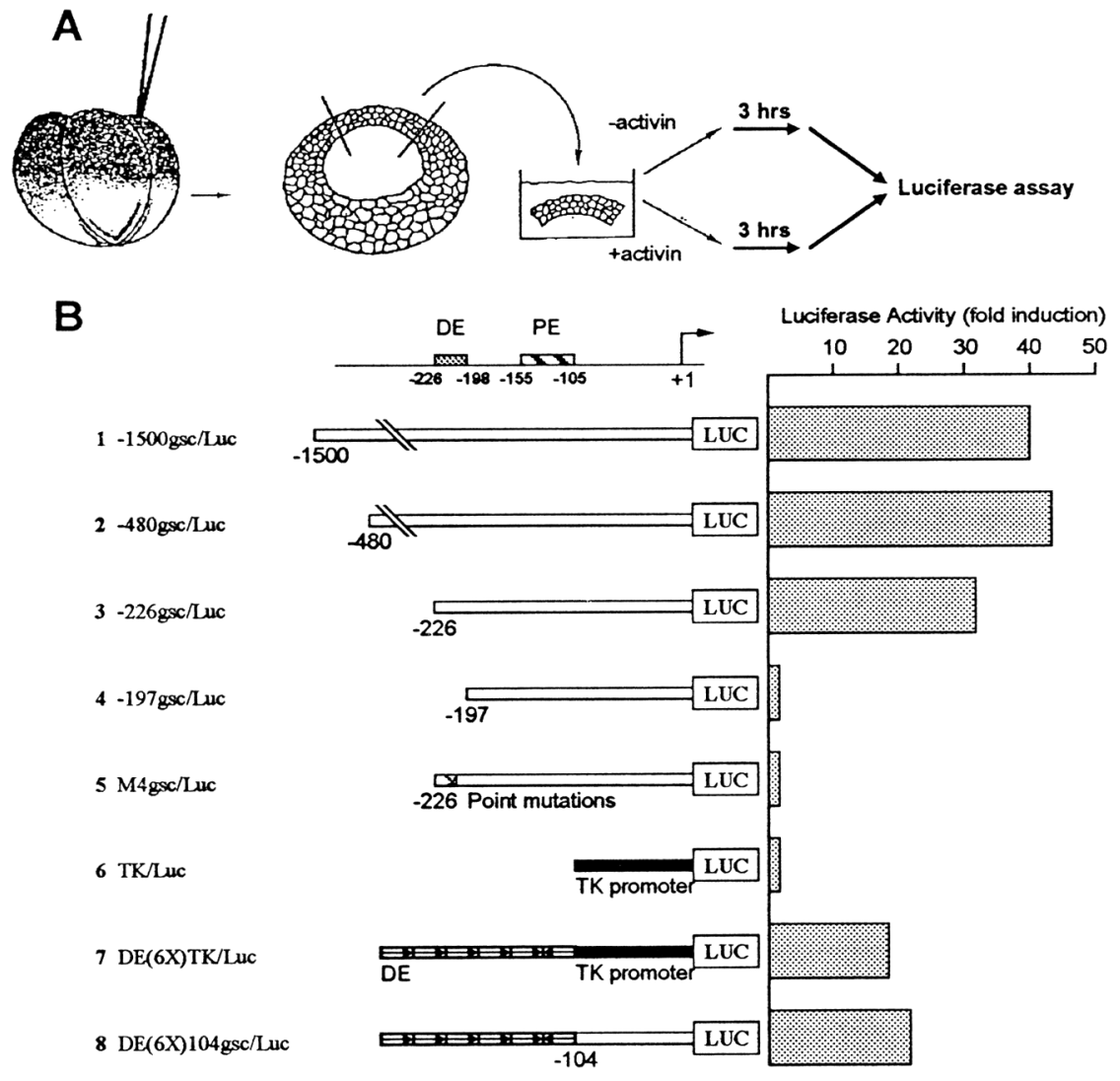

Figure 2. Identification of an activin responsive element within the gsc promoter sequence. (A) Schematic representation of the reporter gene assay in animal caps. Embryos are injected into the animal pole of all blastomeres at the four-cell stage with reporter gene constructs. At the blastula stage, animal caps are dissected manually, cultured for $3 \mathrm{hr}$ in the presence or absence of growth factor (e.g., activin), and subjected to luciferase assays. $(B)$ Deleting sequences between -226 and - 197 dramatically reduces the ability of the gsc promoter to respond to activin in animal cap assays. Point mutations within this region (M4gsc/Luc) also eliminate the activin response, suggesting that an activin response element $(D E)$ is located within this region. Multimerization of this element (constructs 7 and 8 , orientation shown by an arrow) is sufficient for activin responsiveness to the heterologous thymidine kinase (TK) promoter and the endogenous gsc promoter (104gsc/Luc). The putative responsive elements are shown in the schematic at the top. Induction of reporter genes was calculated as the ratio between growth factor-treated and untreated animal caps.

through the DE is protein synthesis independent, reflecting endogenous gsc induction in similar assays. Animal caps injected with $\mathrm{DE}(6 \mathrm{X}) \mathrm{TK} /$ Luc were preincubated for $30 \mathrm{~min}$ with or without $5 \mu \mathrm{g} / \mathrm{ml}$ of cycloheximide before adding activin and incubated for an additional $90 \mathrm{~min}$ before isolating RNA (Rosa 1989). In our hands, these conditions prevented the incorporation of $\left[{ }^{35} \mathrm{~S}\right]$ methionine into proteins by $>95 \%$, as measured by scintillation counting (data not shown). Primer extension analysis of the RNA samples revealed that $\mathrm{DE}(6 \mathrm{X}) \mathrm{TK} /$ Luc was transcribed in the presence of cycloheximide after activin challenge (Fig. 3, lane 3), demonstrating that activin directly induces transcription of $\mathrm{DE}|6 \mathrm{X}| \mathrm{TK} /$ Luc. To date, $\mathrm{DE}$ is the first identified cis-acting element that directly responds to a member of the TGF- $\beta$ superfamily.

The specificity of DE toward various growth factors was also determined. DE(6X)TK/Luc or $-226 \mathrm{gsc} / \mathrm{Luc}$ was microinjected into embryos, and luciferase activities were measured using animal caps cultured in medium containing activin, TGF- $\beta 1$, or bFGF. Alternatively, luciferase assays were carried out on animal caps isolated from embryos that were coinjected with reporter genes and synthetic mRNA encoding XBMP-4 (Xenopus bone morphogenetic protein-4), XBMP-7, Xnr3 (Xenopus nodal-related 3, Smith et al. 1995), or BVg1 (a processed form of $V g 1$; Thomsen and Melton 1993). As shown in Figure 4 , only activin and $\mathrm{BVg} 1$ induced the expression of both reporter genes, whereas TGF- $\beta 1$, XBMP-4, XBMP-7, $\mathrm{Xnr}-3$, and bFGF did not. These results suggest that the
$\mathrm{DE}$ is capable of responding specifically to $\mathrm{BVgl}$ and activin, growth factors known to mimic dorsal mesoderminducing activities.

\section{Activin/BVg1-type signaling is active throughout the entire vegetal hemisphere}

Because DE is able to specifically respond to dorsal signals such as activin and BVgl in vitro, we attempted to determine where these signals would be present in the whole embryo. In Xenopus, the prospective fates of the various blastomeres of the 32-cell stage embryo have been well studied (Fig. 5A; Dale and Slack 1987a). For example, Dl, Cl, and C4 blastomeres give rise predominantly to dorsal endoderm (Nieuwkoop center), dorsal mesoderm (Spemann's organizer), and ventral mesoderm of the embryos, respectively, whereas the blastomeres of the A tier become skin and neural ectoderm. We expected that the activity of $\mathrm{DE} \mid 6 \mathrm{X}) 104 \mathrm{gsc} / \mathrm{Luc}$ (Fig. 2, line 8) might be the highest in the $\mathrm{Cl}$ and Dl blastomeres of 32-cell stage embryos, where the dorsal mesoderm-inducing activity is thought to reside, according to the three-signal model. Unexpectedly, we found that the reporter gene activity of $\mathrm{DE}|6 \mathrm{X}| \mathrm{TK} /$ Luc was uniformly activated (an average of 40-fold) in all blastomeres of the C and $D$ tiers, whereas activities in the blastomeres of the $\mathrm{A}$ and $\mathrm{B}$ tiers were low (Fig. 5B). From these results, we conclude that an activin/BVg1-like activity is uniformly 


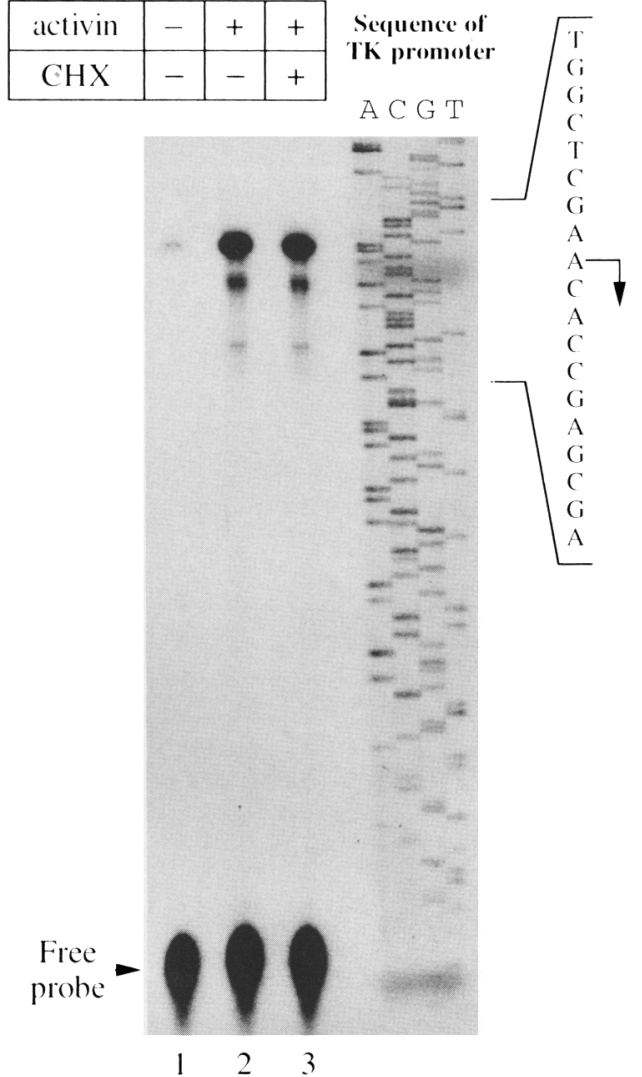

Figure 3. Activin induction of $g s c$ transcription through the $\mathrm{DE}$ is direct. The primer extension analysis of luciferase transcripts shows that faithful transcription from the DE[6X|TK/ Luc reporter gene is induced by activin in the presence of cycloheximide. The DNA sequence ladder was produced using the same primer on the TK/Luc reporter construct. Nucleotide sequence flanking the start site is shown at right, and transcription start site is indicated by an arrow. (Lane 1) No activin or cycloheximide treatment; (lane 2) activin treatment alone; (lane 3) activin and cycloheximide treatment. [See Materials and methods for details).

present, encompassing the entire marginal zone as well as the vegetal hemisphere in the Xenopus embryo.

Response of the gsc promoter in whole embryos: in vivo analysis

The uniform localization of activin/BVgl-like activity in Xenopus embryos prompted us to test the native gsc promoter in blastomere injections because it appeared that DE alone was not sufficient to faithfully recapitulate organizer-specific expression of gsc. Figure 6 shows the results of microinjection of various $g s c$ promoter reporter genes into blastomeres of $\mathrm{A} 4, \mathrm{Cl}$, or $\mathrm{C} 4$. When the $-1500 \mathrm{gsc} /$ Luc reporter construct was injected into the $\mathrm{Cl}$ blastomere, it was activated 297 -fold better than in A4 (Fig. 6, line 1). The $\mathrm{C} 4$ blastomere was also capable of activating the reporter gene at a moderate level (57-fold), probably because of an activin/BVgl activity that is present throughout the entire marginal zone (see Fig. 5B). The selected activation of $-1500 \mathrm{gsc} / \mathrm{Luc}$ in $\mathrm{Cl}$ and $\mathrm{C} 4$ is not attributable to nonspecific activation of the reporter because similar injection of the SV40/Luc, Rous sarcoma virus (RSV)/Luc, mouse mammary tumor virus (MMTV)/Luc, and RSV/ $\beta$-galactosidase failed to exhibit such localized activation (data not shown).

Activation levels of gsc/Luc constructs with $5^{\prime}$ deletions up to position -226 were essentially similar to that of $-1500 \mathrm{gsc} /$ Luc (Fig. 6, line 2). However, when $-197 \mathrm{gsc} /$ Luc (lacking the DE) was injected, reporter gene activity in $\mathrm{Cl}$ was reduced to 40 -fold, and activity in $\mathrm{C} 4$ was reduced to levels similar to those found in A4 (Fig. 6, line 3). The reduction of reporter gene activity in both $\mathrm{Cl}$ and $\mathrm{C} 4$ is consistent with a requirement for the $\mathrm{DE}$ to respond to an activin/BVgl-like signal present throughout the marginal zone. Moreover, the fact that $-197 \mathrm{gsc} / \mathrm{Luc}$ (lacking the DE) is still inducible up to 40-fold in $\mathrm{Cl}$ implies that additional regulatory elements are present downstream of position -197 .

Microinjection of other deletion constructs into $\mathrm{Cl}$ demonstrated that gsc/Luc constructs extending to position -155 are still capable of being induced (Fig. 6, line 4; data not shown). However, further deletions reduced reporter gene activities to basal levels (Fig. 6, line 5), supporting our hypothesis that an additional element is present within the gsc promoter that responds to a dorsal-specific signal.

\section{The PE specifically responds to Xwnt-8 signal}

In addition to mesoderm-inducing molecules, such as activin and BVgl, a competence modifier, $X w n t-8$, is capable of inducing gsc when it is ectopically expressed in the ventral region of gastrulating embryos where mesoderm-inducing activities are also present (Christian and Moon 1993|. Therefore, we examined whether Xwnt-8 was capable of inducing a reporter gene through the $-226 \mathrm{bp}$ of the cloned gsc promoter. Coinjection of $X$ wnt -8 mRNA into ventral blastomeres (C4) with the $226 \mathrm{gsc} /$ Luc reporter construct revealed that Xwnt-8 expression activated the reporter gene 18 -fold higher than in control $\mathrm{C} 4$ blastomeres injected with reporter alone (Fig. 7, lines 1, 2). When the specificity of gsc for Xwnt-8 signaling was examined using another Wnt-related molecule, Xwnt-5A (Moon et al. 1993), Xwnt-5A was unable to activate the $-226 \mathrm{gsc} / \mathrm{Luc}$ reporter gene (see Fig. 7, line 31. The result suggests that the response of gsc to $X w n t-8$ induction is selective. We also examined the timing of $X w n t-8$ action on gsc activation during embryogenesis because ectopic expression of Xwnt-8 mRNA does not distinguish whether the translated protein product acts before or after midblastula transition (MBT). This question is important, because for Xwnt to mimic the Nieuwkoop center activity to induce the organizer the protein must commence its function before (during cleavage stages), but not after MBT (Christian and Moon 1993/. We coinjected $-226 \mathrm{gsc} /$ Luc with a cytoskeletal actin promoter (CSKA)-Xwnt- 8 construct that directs the expression of Xwnt-8 only after MBT and 


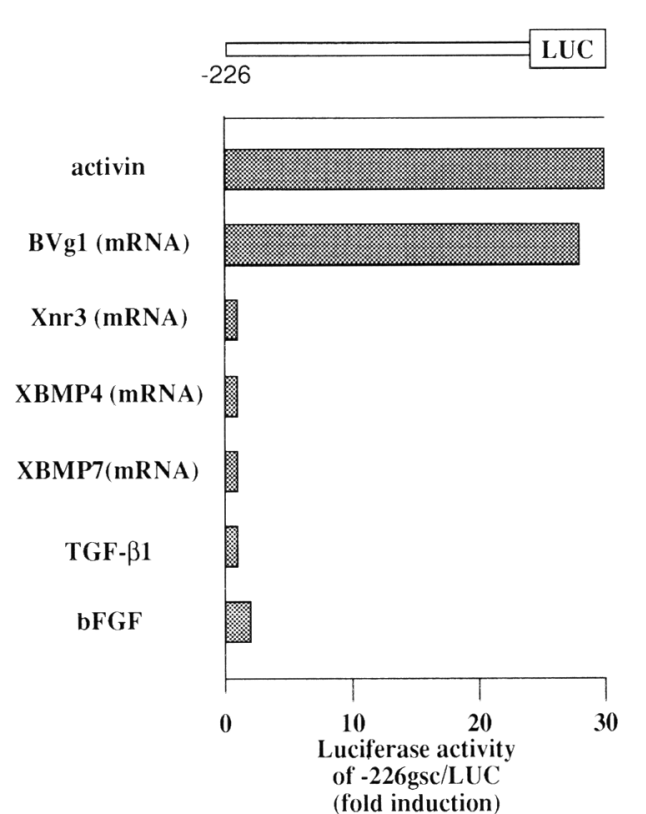

$\mathrm{DE}$

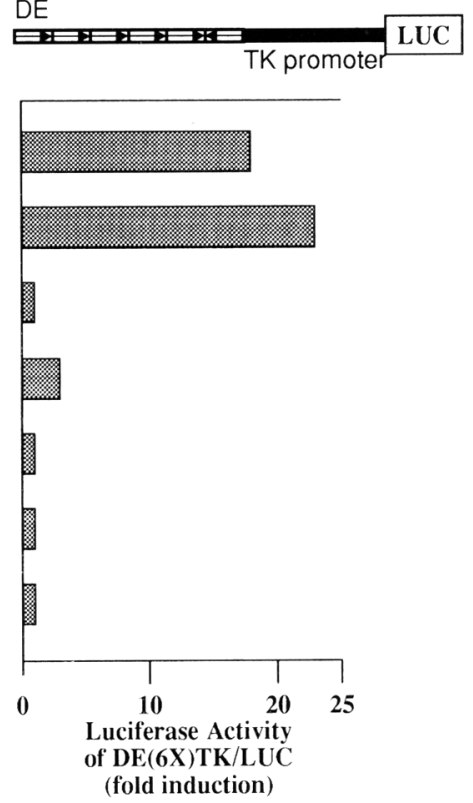

Figure 4. Dorsal signaling molecules specifically activate the DE. Induction of the $-226 \mathrm{gsc} / \mathrm{Luc}$ (left) and DE/6X/TK/Luc (right) reporter constructs was tested in animal caps with various growth factors. The gsc promoter responds specifically to activin and $\mathrm{BVgl}$, molecules that mimic dorsal signals. The DE is sufficient for this response conferring activity to a heterologous promoter. found that CSKA-Xwnt- 8 was unable to activate the reporter gene (Fig. 7, line 4). From this experiment, we infer that ectopic expression of Xwnt- 8 mimics Nieuwkoop center activity, which in turn induces a secondary organizer to activate the $g s c$ reporter gene.

Noggin is present maternally in Xenopus embryos (Smith and Harland 1992), and can also function as a competence modifier. Therefore, we examined the possibility that activation of $g s c$ by $X w n t-8$ mimics endogenous Noggin signaling. Coinjection of $-226 \mathrm{gsc} / \mathrm{Luc}$ with a high concentration of noggin mRNA $(2 \mathrm{ng})$ results in moderate activation of the reporter in $\mathrm{C} 4$ (four-fold) when compared with that of reporter gene injected alone (Fig. 7, line 5). At present. the molecular nature of the weak activation of $g s c$ by noggin is not clear, though our observations are consistent with Lemaire et al. (1995), who demonstrated a stronger axis-inducing activity by $X$ wnt-8 when compared with noggin.

\section{Identification of a Wnt-responsive element within the promoter of the gsc gene}

Because Xwnt- 8 was shown to induce $-226 \mathrm{gsc} /$ Luc reporter gene expression in the ventral side of embryos, we decided to test whether Xwnt-8 induction is dependent on the DE (an activin/BVgl-like signal responsive element). As shown in Figure 8, the $-197 \mathrm{gsc} /$ Luc construct lacking the DE was still responsive to Xwnt-8 induction in the ventral mesoderm $(\mathrm{C} 4)$, despite the overall activity being reduced because of the lack of the DE (cf. Fig. 8, lines 1 and 2). The lack of DE involvement in Xwnt-8 induction is consistent with the finding that the $\mathrm{DE}(6 \mathrm{X}) 104 \mathrm{gsc} /$ Luc construct capable of responding to activin/BVgl fails to respond to the $X w n t-8$ signal (data not shown).

Subsequent analysis revealed that reporter genes con- taining deletions up to position -155 were still capable of responding to the $X w n t-8$ dorsalizing signal but further deletions eliminated the Xwnt- 8 response (Fig. 8, lines 3,4$)$. Because the region downstream of position -155 appeared to be crucial for the $X w n t-8$ response, we generated a series of linker-scanning mutants and tested their responses to Xwnt-8 induction. Mutations in the region between -155 and -105 bp abolished the Xwnt- 8 dorsalization response (data not shown). From these experiments we conclude that there are two distinct cisactivating elements in the gsc promoter, a DE and a PE, that respond to two different types of growth factor signals, namely an activin/BVg1 type and an Xwnt-8-type, respectively. It appears that spatiotemporal expression of the gsc gene is controlled via the DE and PE through the combinatorial actions of a general mesoderm inducer and a competence modifier to elicit a dorsal signal. This mechanism of growth factor synergy may broadly reflect how the organizer is established in amphibians.

\section{The DE and PE are conserved between the Xenopus and mouse gsc genes}

Isolation and comparison of the genomic counterpart of the Xenopus gsc promoter in the mouse have identified two highly conserved regions (Fig. 9A). The DE between -226 and $-197 \mathrm{bp}$ in Xenopus is $87 \%$ identical to a sequence located between $-582 \mathrm{bp}$ and $-554 \mathrm{bp}$ in the mouse gsc promoter, and the Xenopus PE between -151 and $-105 \mathrm{bp}$ is $70 \%$ identical to a mouse sequence between -524 and -474 bp (Fig. 9A). The conservation of both the DE and PE between Xenopus and mouse suggests that molecular mechanisms supporting gsc regulation may have been preserved during evolution.

Because both the mouse and Xenopus gsc genes are inducible by activin (Cho et al. 1991; Blum et al. 1992) 
A

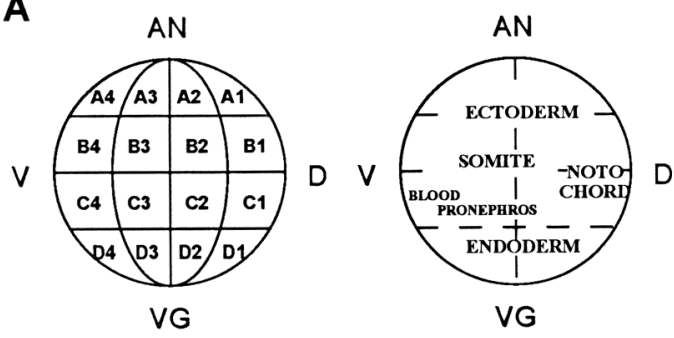

B

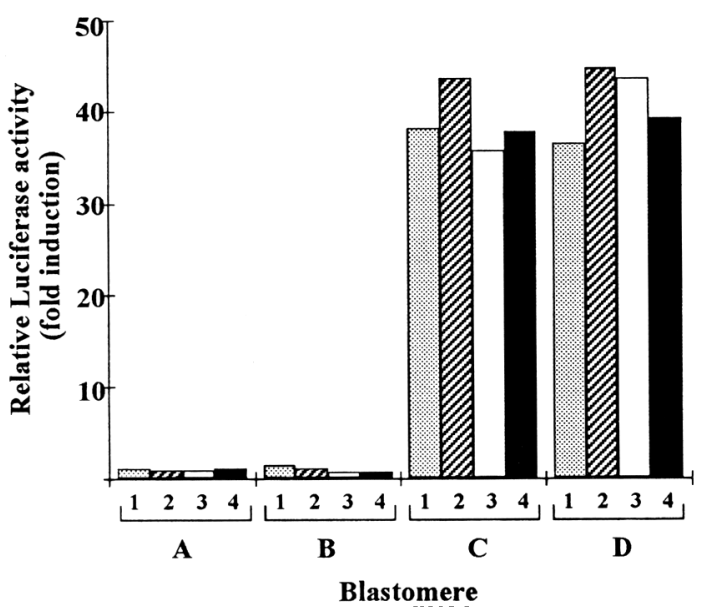

Figure 5. Localization of the activin/BVg1-like signals in the embryo. (A) Blastomere nomenclature (left) and fate map (right) of a Xenopus 32-cell stage embryo according to Dale and Slack (1987a). (AN) Animal pole; (VG) vegetal pole; (D) dorsal; (V) ventral. $|B|$ A single blastomere at the 32-cell stage was injected with $\mathrm{DE}(6 \mathrm{X}) 104 \mathrm{gsc} /$ Luc. The activity of a pool of five embryos injected into the same blastomere indicates that an activin/ $\mathrm{BVgl-like}$ activity is present uniformly throughout the marginal and vegetal regions of the embryo during early gastrulation (stage 10.5) when the luciferase assay was performed. Activity is presented as a ratio of induction over A4 blastomere activity, which we consider baseline activity. At present, we cannot determine whether induction of the reporter gene in the $\mathrm{C}$ tier occurs through signals present in situ or emanating from the $D$ tier. and the sequences of the DE and PE are conserved between the two species, we studied the extent of functional conservation of the DE and PE by examining the effect of the mouse gSC promoter sequence in the Xenopus in vitro and in vivo systems. Mouse gsc promoter sequence corresponding to the region of the Xenopus gsc promoter between -226 and -105 bp (containing both the DE and PE) was cloned upstream of Xenopus $-104 \mathrm{gsc} /$ Luc (the minimal gsc promoter/Luc construct). The response of the resulting construct (mDE$\mathrm{PE} / 104 \mathrm{gsc} / \mathrm{Luc}$ ) to activin was measured in animal caps. As shown in Figure 9B, the mouse promoter sequence responded to activin challenge to the same extent as its Xenopus counterpart, whereas the minimal gsc promoter did not.

We further tested the functional conservation of the mouse gSC promoter sequence by examining the response of $\mathrm{mDE}-\mathrm{PE} / 104 \mathrm{gsc} / \mathrm{Luc}$ to endogenous factors in the Xenopus embryo and to ectopic expression of Xwnt-8 using blastomere coinjection assays. As shown in Figure 9C, the activities of the mouse gsc promoter construct in Xenopus were indistinguishable to those of its Xenopus counterpart (lines 1,2). Moreover, we found that the mouse gSC construct responded to Xenopus Xwnt-8 induction as revealed by increased reporter gene activity in $X$ wnt-8-injected $\mathrm{C} 4$ blastomeres. These results demonstrate that the DE and PE are structurally and functionally conserved between both the mouse and Xenopus gsc promoter. The interchangeability of these elements between the two species supports the notion that intracellular signaling mechanisms leading to the formation of organizer-equivalent tissues in vertebrates are likely to have been preserved during evolution.

\section{Discussion}

Characterization of the gsc promoter has identified important cis-acting elements whose control most likely reflects the regulation involved in establishing the organizer. The $D E$ is the first response element shown to be directly inducible by a TGF- $\beta$ signaling molecule. Re-
Figure 6. The DE and a more proximal element (PE) recapitulate endogenous gsc expression. A single $\mathrm{A} 4, \mathrm{Cl}$, or $\mathrm{C} 4$ blastomere was injected at the 32 -cell stage with the indicated deletion constructs, and the reporter gene activity was measured as described in Materials and methods. The blastomere activity of $-1500 \mathrm{gsc} / \mathrm{Luc}$ is similar to that of $-226 \mathrm{gsc} /$ Luc. As shown previously in vitro (Fig. 2), deletion of the DE dramatically reduces the level of induction by an activin/BVgl-like activity in both $\mathrm{Cl}$ and $\mathrm{C} 4$ blastomeres. However, induction of gsc promoter still occurred in the dorsal blastomere $(\mathrm{C} 1)$ independent of the DE (lines 3,4 ), suggesting the presence of an additional element (downstream of position -155 ) that may respond to dorsal-specific signals.

\section{$1-1500 \mathrm{gsc} /$ Luc}

2 -226gsc/Luc

$3-197 g s c / L u c$

$4-155 g s c / L u c$

5 -104gsc/Luc
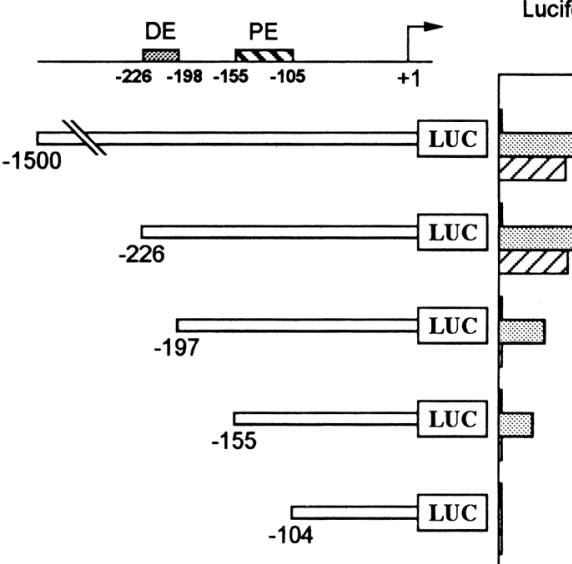

Luciferase Activity (fold induction)

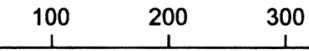

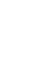

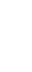

.

(n)




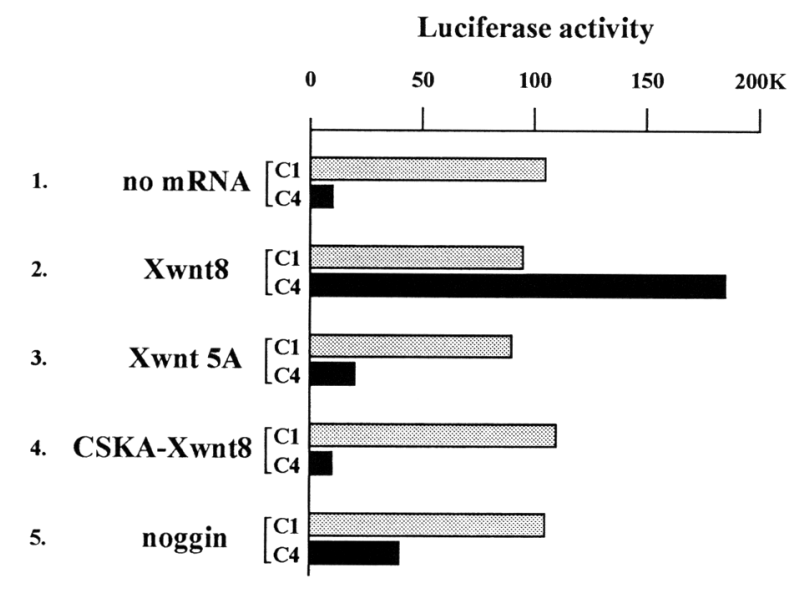

Figure 7. Ectopic Xwnt-8 specifically activates the gSC promoter. The construct $-226 \mathrm{gsc} /$ Luc was either injected alone or coinjected with the indicated mRNAs or DNA into either the dorsal (C1) or ventral (C4) blastomere of the 32-cell stage embryos, and the reporter gene activity was measured. Comparison of $\mathrm{C} 1$ - and C4-injected embryos with the reporter gene revealed that the $\mathrm{Cl}$-injected embryos induce the reporter gene $\sim 10$-fold higher than the C4-injected embryos. Coinjection of Xwnt-8 mRNA caused an 18-fold induction of the reporter gene in the $\mathrm{C} 4$ blastomere, which is indicative of dorsalization of the blastomere. This induction was specific for $X w n t-8$, as other Wnt molecules and competence modifiers (lines 3,4,5) did not induce the gsc promoter. When Xwnt-8 mRNA was coinjected dorsally, the reporter gene induction was not observed presumably because of the presence and maximal levels of a natural dorsal signal. Data presented are actual luciferase counts. It should be noted that the reporter gene activity in $\mathrm{C} 4$ after $X w n t-8$ injection was consistently higher than that of $\mathrm{Cl}$, whose significance is unknown at present.

porter constructs containing the DE indicate that an activin/BVgl-type signaling cascade is active throughout the vegetal and marginal regions, which is inconsistent with the notion that this activity should be localized to the dorsovegetal region (Nieuwkoop center) of Xenopus embryos (Green et al. 1992). This suggests that an activin/BVgl-like activity may have a more general role in mesoderm induction than indicated by previous models. Downstream of the DE is a Wnt-responsive element, the $P E$, which appears to be specific for a dorsal signal mimicked by ectopic expression of Xwnt-8. Together, the DE and PE can synergistically activate the gsc promoter in the dorsal region of the embryo where their respective signal pathways converge.

\section{A current working model of organizer formation: growth factor synergism}

In this paper we provide in vivo evidence supporting a model whereby dorsal mesoderm and Spemann's organizer are established by growth factor synergism as shown in Figure 10 (Christian et al. 1992; Kimelman et al. 1992). According to the model, an interaction between general mesoderm-inducing factors, such as activin/BVgl-like molecules, and competence modifiers, such as $X w n t-8$, would be capable of producing dorsal types of mesoderm. Synergistic activation of gsc by $X w n t-8$ and activin has been suggested from experiments in vitro using animal cap tissues /Sokol and Melton 19921. Furthermore, Wnt signaling has been implicated in establishing dorsal mesoderm by two independent observations: Oligonucleotide ablation of $\beta$-catenin during Xenopus development eliminates dorsal mesoderm (Heasman et al. 1994), and ectopic expression of Xenopus and Drosophila dishevelled, another component of Wnt signaling, activates the gsc promoter (Rothbächer et al. 1995; U. Rothbächer and K. Cho, unpubl.). In support of these observations, we have demonstrated that the promoter of gsc contains two independent cis-regulatory elements, one each for activin/BVgl and Xwnt-8 (Fig. 10). The DE is sufficient to respond to the general mesoderm signal (activin/BVgl-like signal), which is active throughout the vegetal hemisphere of the embryo. When both elements are together, synergistic activation of the

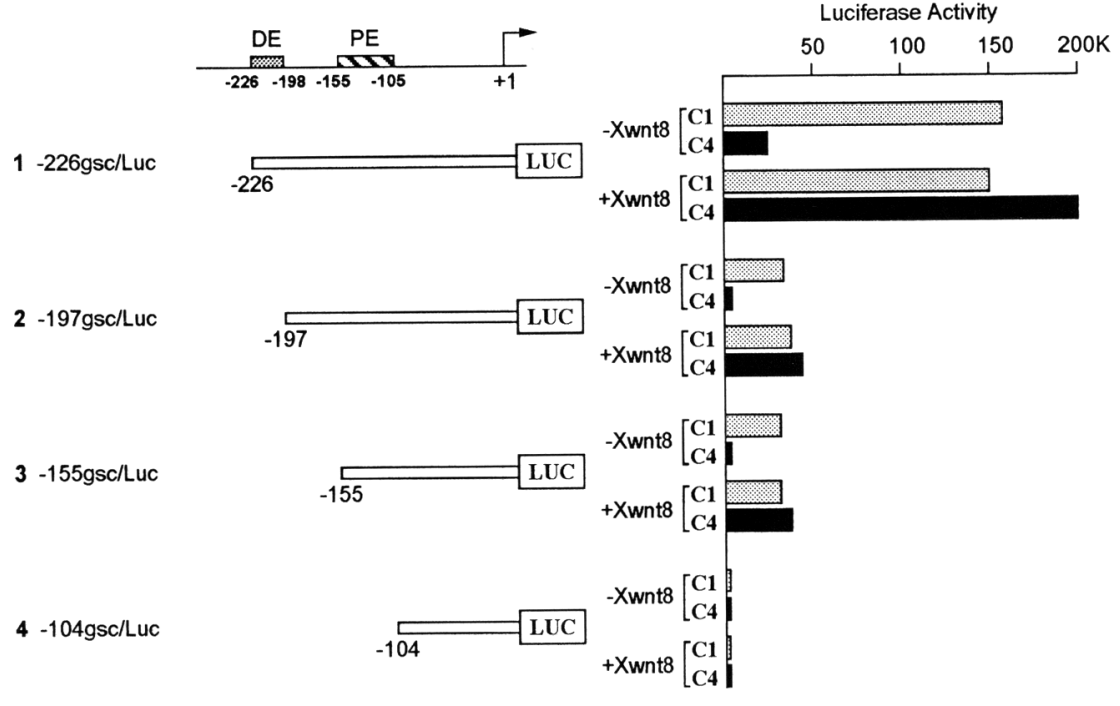

Figure 8. Identification of a Wnt-responsive element within the gsc promoter sequence. Deletion constructs were injected into the $\mathrm{Cl}$ (dorsal), and $\mathrm{C} 4$ (ventral) blastomeres at the 32 -cell stage in the presence or absence of synthetic Xwnt-8 mRNA. A Wnt-responsive element is located downstream of position -155 (line 3 ), as both $-197 \mathrm{gsc} /$ Luc and $-155 \mathrm{gsc} /$ Luc /constructs which do not contain the DE) continue to respond to $X$ wnt -8 when coinjected ventrally (C4). Actual luciferase activities are presented. 
A

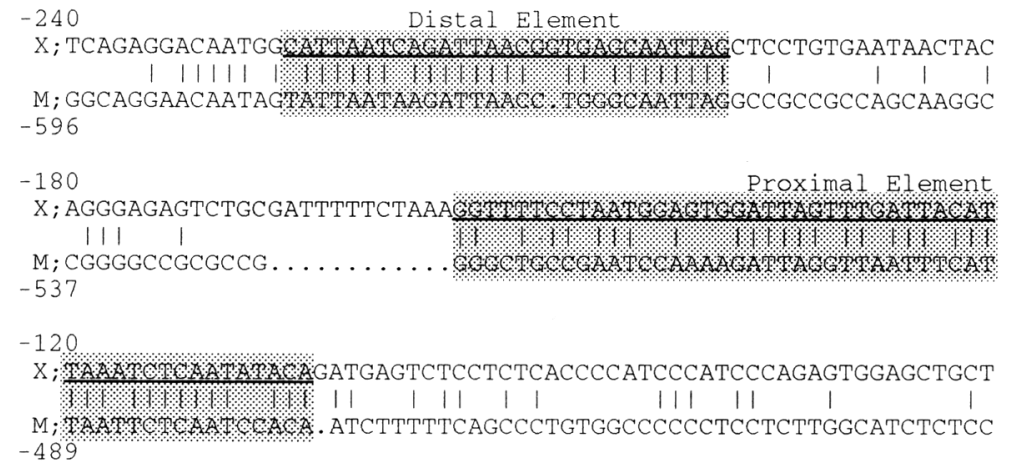

B

Figure 9. The gsc DE and $\mathrm{PE}$ are homologous between Xenopus and mouse. (A) Sequence comparison of Xenopus and mouse gsc promoter sequences with optimal alignment of the DE and PE using MacVector's Pustell DNA matrix search (IBI). Identities are shown by vertical bars. Gaps introduced to align the sequences are marked by dots. The Xenopus and mouse DE and $\mathrm{PE}$ are $83 \%$ and $70 \%$ identical, respectively. $|\mathrm{X}|$ Xenopus; (M) mouse. The nucleotide positions for the mouse $\mathrm{DE}$ and $\mathrm{PE}$ are relative to the translational start site. The GenBank accession number for the mouse gsc promoter sequence is U39290. (B) Animal cap assays using the $-226 \mathrm{gsc} / \mathrm{Luc}$ (Xenopus DE-PE) and $\mathrm{mDE}-\mathrm{PE} /$ $104 \mathrm{gsc} /$ Luc (mouse DE-PE) reporter genes indicate that the mouse and Xenopus DE-PE have an equivalent response to activin. Activity represents fold induction over untreated animal caps isolated from embryos injected with the same constructs. $|C|$ Similarly, the Xenopus and mouse DE-PE respond equally to endogenous signals and ectopic $X w n t-8$ expression in blastomere injection experiments.

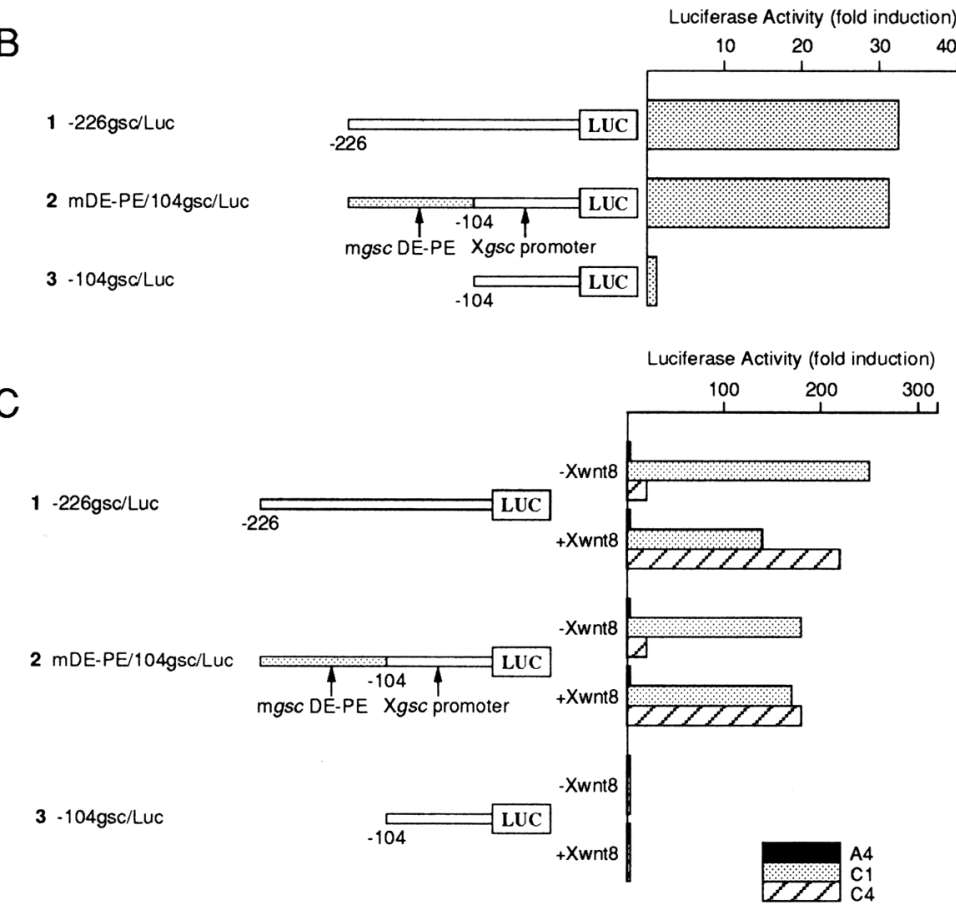

promoter in dorsal mesoderm is found in vivo (Fig. 10). The model predicts that the endogenous gsc gene is expressed at high levels in the dorsal-most tissue of the embryo, and that it should be expressed at low levels throughout the rest of the marginal and vegetal region because of the presence of an activin/BVgl-like activity in these regions. However, the expression of gsc in the ventral/lateral marginal region, for example, may be modified further by the presence of other molecules such as BMP-4 and BMP-7 that are expressed in the ventral/ lateral marginal zone and known to suppress the expression of gsc (Fainsod et al. 1994; Graff et al. 1994; Suzuki et al. 1994; Hawley et al. 1995; Schmidt et al. 19951. Additionally, synergistic and modifying roles for FGF in establishing the mesoderm (Labonne and Whitman 1994; Cornell et al. 1995) may also influence the regulation of $g s c$ in the marginal zone.

The synergistic induction model of mesoderm forma- tion is attractive for several reasons. First, it explains how ectopic expression of Xwnt-8 in animal pole cells (A4 injection) fails to induce the gsc reporter gene, whereas injection into the ventral marginal zone leads to strong expression of $g s c$ on the ventral side $(\mathrm{C} 4$ blastomere injection|. As we have demonstrated, the A tier does not contain an activin/BVgl-like activity (Fig. 5B) and, therefore, could not synergize with $X w n t-8$ as it does in the $\mathrm{C} 4$ blastomere. Second, the model provides a molecular basis for the quantitative differences in the levels of $g s c$ reporter gene induction observed when comparing activin-treated animal caps with blastomere injections. That is, we show that $-226 \mathrm{gsc} / \mathrm{Luc}$ is activated only $\sim 30$ - to 50 -fold in activin-treated animal caps, whereas in blastomere injection assays, the reporter gene was activated as much as 300-fold (Cl/A4 ratio; Fig. 6). Perhaps, the animal cap lacks a Wnt-type activity that appears to be localized in the dorsal region of the em- 

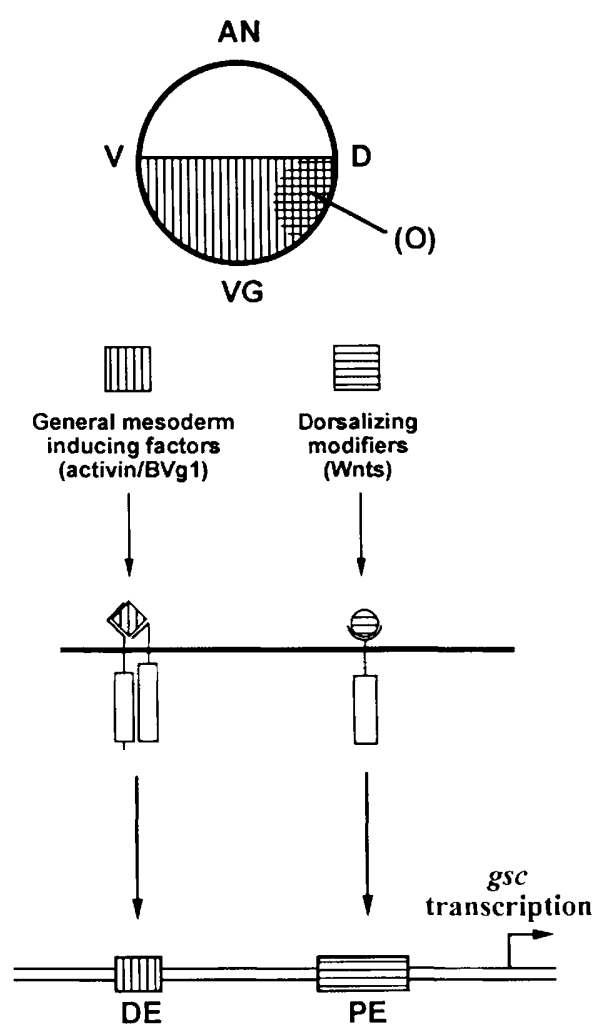

Figure 10. A current working model of Spemann's organizer formation. A map of gsc promoter activity found at gastrulation suggests that during mesoderm formation a general mesoderminducing activity, provided by an activin/BVgl-like activity |vertically lined areal, would be present throughout the marginal and vegetal region, whereas a dorsalizing activity (horizontally lined areal, mimicked by $X w n t-8$, would be localized to establish organizer tissue. The map is reminiscent of the synergism model of mesoderm formation described by Moon and Christian (1992), supporting a proposal that growth factor synergy may be a common mode of regulation for genes expressed in the organizer. The two independent signaling cascades synergize to induce $g s c$ gene expression through two independent cis-acting elements within the gsc promoter. This regulation appears to be conserved between mouse and Xenopus and may reflect a general mechanism for establishing organizing centers in vertebrates. At present, the model does not take into account other regulatory factors, such as BMPs, which appear to directly affect transcription of organizer genes as well. (AN) Animal pole; $(V G)$ vegetal pole; $(D)$ dorsal; $(V)$ ventral; $(O)$ presumptive organizer region.

bryo. Third, as mentioned previously, the model explains the weaker activation of $-226 \mathrm{gsc} / \mathrm{Luc}$ in C4, because of an activin/BVgl-like activity present throughout the vegetal and marginal regions of the embryo. Finally, the model can account for the regional specification of early gastrula embryos via a single or limited number of inducing molecules in cooperation with differentially localized competence modifiers. Synergistic activation of different target genes within each territory could be obtained to define regional characteristics of the embryo.
Molecular mechanisms underlying organizer formation are conserved during vertebrate evolution

Gastrulation is possibly the most crucial event of vertebrate development. It is at this stage that the three germ layers (ectoderm, mesoderm, and endoderm) undergo a series of morphogenetic movements that initiate the various cell-cell interactions and inductions that establish the embryonic axis. Each member of the five vertebrate classes undergoes its own distinct morphogenetic movements. However, after the completion of gastrulation, most vertebrate embryos exhibit remarkably similar features (von Baer 1828).

Although gastrulation processes appear different among various species, the fundamental mechanisms regulating gastrulation appear to be conserved across the chordate phylum. Homologs for gsc have been identified in such disparate vertebrate species as mouse, chicken, and zebrafish. In all of these organisms, gsc transcripts appear at the onset of gastrulation precisely in the region where cell ingression is initiated. gsc is expressed in the dorsal lip in Xenopus (Cho et al. 1991), the dorsal blastoderm in zebrafish (Stachel et al. 1993), Koller's sickle and Hensen's node in chicken (Izpisua-Belmonte et al. 1993), and the primitive streak in mouse (Blum et al. 1992). These findings and similar results obtained from comparative studies of Brachyury gene expression (Herrmann 1991; Smith et al. 1991; Schulte-Merker et al. 1992) suggest conservation of the molecular framework governing gastrulation among different species.

Our analysis of $g s c$ regulation revealed that in addition to the conserved expression of the gsc homeo box gene during gastrulation, the molecular mechanisms that underlie the induction of gsc are also conserved among vertebrates. The regulatory DNA elements conserved between the mouse and Xenopus gsc genes are functionally interchangeable, suggesting that the signals and the signaling pathways for forming organizing centers are likely to be conserved among vertebrates at the most basic biochemical levels. Further analysis of components of the signal transduction pathways (e.g., DNA-binding proteins for the DE/ will give additional insight into this conservation.

\section{Material and methods}

Construction of expression plasmids

A Xenopus gsc genomic clone has been described previously (Cho et al. 1991). The $-1500 \mathrm{gsc} /$ Luc reporter was constructed from a blunt-ended EcoRV-PstI 1.5-kb Xenopus gsc gene fragment carrying $3 \mathrm{bp}$ of exon 1 and $5^{\prime}$-promoter sequences inserted into the SmaI site of the promoterless luciferase vector pOLuc (de Wet et al. 1987).

Fragments for the deletion constructs were generated by PCR using the same $3^{\prime}$ (downstream) primer (nucleotides -5 to +12 relative to the transcription start site) and various $5^{\prime}$ (upstream) primers representing a series of deletions in the gsc promoter region. The 3 ' primer contained a HindIII restriction site at its $5^{\prime}$ terminus and the $5^{\prime}$ primers contained a $\mathrm{BamHI}$ restriction site at their $5^{\prime}$ termini for directional cloning into pOLuc. The upstream primer for construction of M4gsc/Luc 
had six single-base mutations in the region between -226 and -210 . Sequences of the PCR primers are listed below Downstream primer: 5' GGGAAGCTTCAGACTGCAGTCCTCTT-3'. Upstream primers for $-226 \mathrm{gsc} /$ Luc, 5'-GGGGGATCCCATTAATCAGATTAACG-3'; $-203 \mathrm{gsc} /$ Luc, $5^{\prime}$-GGGGGATCCAATTAGCTCCTGTGAAT-3'; $-180 \mathrm{gsc} / \mathrm{Luc}, 5^{\prime}-$ GGGGGATCCAGGGAGAGTCTGCGATT-3'; - 155gsc/Luc, 5'-GGGGGATCCGGTTTTCCTAATGGAGT-3' ${ }^{\prime}$ - 104gsc/Luc, 5'GGGGGATCCGGTTTTCCTAATGGAGT-3'; $\mathrm{M} 4 \mathrm{gsc} / \mathrm{Luc}$,

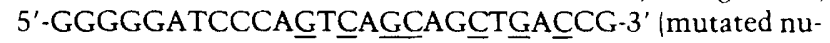
cleotides are underlined).

To prepare the multimers of the DE, a set of two oligonucleotides, DE.L $\left\{5^{\prime}\right.$-GATCTCATTAATCAGATTAACGGTGAGCAATTAG-3') and DE.R (5'-GATCCTAATTGCTCACCGTTAATCTGATTAATGA-3') were synthesized. They were phosphorylated, annealed, and concatenated as described (Kadonaga 1986). The multimers were subcloned into the BamHI site of the TK luc-based plasmid and - 104pOLuc, and the presence of six copies of the DE was determined by sequencing.

To prepare mDE-PE/104gsc/Luc, the fragment of the mouse counterpart of the Xenopus gsc 5'-flanking sequence between -226 and -105 was generated by PCR using primers that contained a BamHI restriction site at their $5^{\prime}$-termini. The sequences of the PCR primers are upstream, 5'-GGGGGATCCTATTAATAAGATTAACC-3'; and downstream, 5'-GGGGGATCCTGTGGATTGAGAATTA-3'. The PCR fragment was subcloned into the BamHI site of $-104 \mathrm{gsc} /$ Luc. All subclones were sequenced using Sequenase (U.S. Biochemicall.

\section{Preparation of synthetic RNA}

The plasmids pSP64T-BVg-1 (Thomsen and Melton 1993), Xßm-BMP-4, Xßm-BMP-7 (Hawley et al. 1995), Xnr3/pGEM5 (Smith et al. 1995), X $\beta \mathrm{m}-X w n t-8$ (Christian et al. 1992), X $\beta \mathrm{m}$ Xwnt-5A (Moon et al. 1993), and pSP64T-noggin (Smith and Harland 1992) were linearized as described previously. Capped mRNAs were synthesized using the Megascript transcription kit (Ambion) and were resuspended in injection buffer $188 \mathrm{~mm}$ $\mathrm{NaCl}, 1 \mathrm{~mm} \mathrm{KCl}, 15 \mathrm{~mm}$ Tris- $\mathrm{HCl}$ at $\mathrm{pH} 7.5$.

\section{Luciferase assay}

Animal caps and embryos were collected and excess medium was removed. Tissues were homogenized in $100 \mu \mathrm{l}$ of $50 \mathrm{~mm}$ Tris $(\mathrm{pH} 7.6)$ and cleared by centrifugation. Ten microliters of the supernatant was assayed for luciferase activity according to the manufacturer's recommendation (Analytical Luminescence Laboratory) in a Berthold luminometer. Each luciferase sample contained an extract of 10 animal caps or 5 whole embryos. Experiments were repeated at least three times. One representative experiment is shown for each figure. Because absolute levels of reporter gene activity were influenced by the batch of eggs, each experiment was carried out using eggs laid by a single female.

\section{Xenopus embryo handling and manipulation}

Xenopus embryos were obtained by artificial fertilization, dejellied in $2 \%$ cysteine hydrochloride, reared in $0.1 \times$ modified Barth saline, (MBS) and staged according to Nieuwkoop and Faber (1967).

For animal cap assays embryos were microinjected into each blastomere at the four-cell stage in the animal pole with $2-4 \mathrm{nl}$ of DNA, and animal caps isolated at the blastula stage (stage 8). The DNA concentration used for injection was $5 \mu \mathrm{g} / \mathrm{ml}$ for TKLuc-based plasmids and $20 \mu \mathrm{g} / \mathrm{ml}$ for pOLuc-based plasmids.
Synthetic BVg-1, Xnr-3, and Xenopus BMP-4, and BMP-7 mRNAs were coinjected at $50-100 \mu \mathrm{g} / \mathrm{ml}$. Alternatively, animal caps were treated with activin, bFGF or TGF- $\beta 1$ (200 ng/ $\mathrm{mll}$. At each of the concentrations, the growth factors are able to elicit functional responses. Isolated animal caps were cultured for $3 \mathrm{hr}$, followed by luciferase assays.

Protein synthesis inhibition was carried out essentially as described by Rosa (1989). To measure the effectiveness of cycloheximide in blocking protein synthesis, animal caps isolated at stage 8 were preincubated with cycloheximide for $30 \mathrm{~min}$ then incubated for $30 \mathrm{~min}$, in $1 \times \mathrm{MBS}$ containing $\left[{ }^{35} \mathrm{~S}\right]$ methionine $(400 \mu \mathrm{Ci} / \mathrm{ml})$, together with cycloheximide and activin, followed by another $30 \mathrm{~min}$ incubation in $1 \times$ MBS containing $\left[{ }^{35} \mathrm{~S}\right.$ ]methionine $(400 \mu \mathrm{Ci} / \mathrm{ml})$ and activin. Animal caps were then homogenized in $50 \mathrm{~mm}$ Tris $(\mathrm{pH} 7.6)$ and cleared by centrifugation. A $2-\mu l$ aliquot of the supernatant was hydrolyzed at $37^{\circ} \mathrm{C}$ for $30 \mathrm{~min}$ in $0.25 \mathrm{ml}$ of $1 \mathrm{~N} \mathrm{NaOH}$ and aminoacyl tRNAs, followed by TCA precipitation and scintillation counting. Other aliquots were used for RNA preparation.

In blastomere injection assays, determination of dorsal versus ventral blastomeres was accomplished as described /Cho et al. 1991). Two nanoliters of DNA was injected into single A1, Cl or C4 blastomeres at the 32-cell stage without or with $200-400$ pg of synthetic mRNA of Xwnt $-8, X w n t 5-A$, or noggin or the DNA expression vector CSKA-Xwnt-8. Embryos were harvested at early gastrula stage (stage 10.5 ) for luciferase assays.

\section{Primer extension analysis}

The transcriptional start site of the luciferase mRNA from the reporter constructs was determined by primer extension (Maniatis et al. 1982) using a polynucleotide kinase end-labeled oligonucleotide that was complementary to nucleotides 22-39 of the luciferase-coding region (de Wet et al. 1987). Template RNA was isolated from animal caps using TRIsol according to the manufacturer's recommendations (GIBCO BRL).

\section{Isolation of genomic clones containing mouse gsc sequences}

An 250-bp PCR fragment of mouse gsc gene exon 1 sequence was amplified from mouse genomic DNA (Clonetech) using two primers containing BamHI linkers. The sequence of the upstream primer was 5'-GGGGGATCCATGTTCAGCATCGACAAC- $3^{\prime}$. The sequence of the downstream primer was $5^{\prime}-$ GGGGGATCCCCGTAGAAGTAGCTGTTGTA-3'. The PCR fragment was used as a probe to screen $\sim 1 \times 10^{5}$ plaques of a genomic mouse library (Strategene), which resulted in the isolation of a $3.3-\mathrm{kb}$ gsc genomic fragment. Hybridizations were carried out in buffer containing $6 \times \mathrm{SSC}, 5 \times$ Denhardts solution, $45 \%$ formamide, $0.1 \%$ SDS, $50 \mathrm{~mm}$ phosphate buffer $(\mathrm{pH} 7.6)$, $100 \mu \mathrm{g} / \mathrm{ml}$ of yeast torula RNA, and $5 \%$ dextran at $37^{\circ} \mathrm{C}$. The final washes were perfomed in $0.5 \times \mathrm{SSC}$ at $50^{\circ} \mathrm{C}$ for $30 \mathrm{~min}$.

\section{Acknowledgments}

We are grateful to I. Christian and $\mathrm{R}$. Moon for the $X \beta \mathrm{m}-X w n t$ 8 , CSKA-Xwnt -8 , and $X \beta m-X w n t-5 A$ constructs, $W$. Smith and R. Harland for the pSP64T-noggin and Xnr3/pGEM5 constructs, and $Y$. Etoh and Genentech for activin. We also thank $\mathrm{K}$. Umesono and R. Evans for the CMV-Luc, SV40/Luc, and RSV/ Luc constructs. We thank M. Artinger, I. Blitz, S. Hawley, and $M$. Laurent for critical comments. The initial screening and sequencing of the gsc promoter was carried out in Dr. E. DeRobertis' laboratory (University of California at Los Angeles). U.R. was supported by Boehringer Ingelheim Fonds. C.H and K.I 
were supported by Japan Society for the Promotion of Science. The work was supported by grants from the National Institutes of Health, March of Dimes, American Cancer Society, and Pew Scholars Program (to K.W.Y.C).

The publication costs of this article were defrayed in part by payment of page charges. This article must therefore be hereby marked "advertisement" in accordance with 18 USC section 1734 solely to indicate this fact.

\section{References}

Ariizumi, T., K. Sawamura, H. Uchiyama, and M. Asashima. 1991. Dose and time-dependent mesoderm induction and outgrowth formation by activin $\mathrm{A}$ in Xenopus laevis. Int.. . Dev. Biol. 35: 407-414.

Blum, M., S.J. Gaunt, K.W.Y. Cho, H. Steinbeisser, B. Blumberg, D. Bittner, and E.M. DeRobertis. 1992. Gastrulation in the mouse: The role of the homeobox gene goosecoid. Cell 69: 1097-1106.

Cho, K.W.Y., B. Blumberg, H. Steinbeisser, and E.M. DeRobertis. 1991. Molecular nature of Spemann's organizer: The role of the Xenopus homeobox gene goosecoid. Cell 67: 11111120 .

Christian, J.L., and R.T. Moon. 1993. Interactions between $X w n t-8$ and Spemann organizer signaling pathways generate dorsoventral pattern in the embryonic mesoderm of Xenopus. Genes \& Dev. 7: 13-28.

Christian, J.L., J.A. McMahon, A.P. McMahon, and R.T. Moon. 1991. Xwnt-8, a Xenopus wnt-1/int-1-related gene responsive to mesoderm-inducing growth factors, may play a role in ventral mesodermal patterning during embryogenesis. Development 111: 1045-1055.

Christian, J.L., D.J. Olson, and R.T. Moon. 1992. Xwnt-8 modifies the character of mesoderm induced by bFGF in isolated Xenopus ectoderm. EMBO /. 11: 33-41.

Cornell, R.A., T.J. Musci, and D. Kimelman. 1995. FGF is a prospective competence factor for early activin-type signals in Xenopus mesoderm induction. Development 121: 24292437.

Cui, Y., J.D. Brown, R.T. Moon, and J.L. Christian. 1995. Xwnt8 b: a maternally expressed Xenopus Wnt gene with a potential role in establishing the dorsoventral axis. Development 121: 2177-2186.

Dale, L. and I.M. Slack. 1987a. Fate map for the 32-cell stage of Xenopus laevis. Development 99: 527-551.

- 1987b. Regional specification within the mesoderm of early embryos of Xenopus laevis. Development 100: 279295.

Dale, L., G. Matthews, and A. Colman. 1993. Secretion and mesoderm inducing activity of the TGF $\beta$ related domain of Xenopus Vg1. EMBO I. 12: 4471-4480.

de Wet, J.R., K.V. Wood, M. DeLuca, D.R. Helinski, and S. Subramani. 1987. Firefly, luciferase gene: Structure and expression in mammalian cells. Mol. Cell. Biol. 7: 725-737.

Fainsod, A., H. Steinbeisser, and E.M. DeRobertis. 1994. On the function of BMP-4 in patterning the marginal zone of the Xenopus embryo. EMBO I. 13: 5015-5025.

Graff, J.M., R.S. Thies, J.J. Song, A.J. Celeste, and D.A. Melton. 1994. Studies with a Xenopus BMP receptor suggest that ventral mesoderm-inducing signals override dorsal signals in vivo. Cell 79: 169-179.

Green, J.B.A., H.V. New, and J.C. Smith. 1992. Responses of embryonic Xenopus cells to activin and FGF are separated by multiple dose thresholds and correspond to distinct axes of the mesoderm. Cell 71: 731-739.
Gurdon, J.B., P. Harger, A. Mitchell, and P. Lemaire. 1994. Activin signalling and response to a morphogen gradient. $\mathrm{Na}$ ture 371: 487-492.

Hawley, S.H.B., K. Wünnenberg-Stapleton, C. Hashimoto, M.N. Laurent, T. Watabe, B. Blumberg, and K.W.Y. Cho. 1995. Disruption of BMP signals in embryonic Xenopus ectoderm leads to direct neural induction. Genes \& Dev. 9: 2923-2935.

Heasman, J., A. Crawford, K. Goldstone, P. Garner-Hamrick, B. Gumbiner, P. McCrea, C. Kintner, C. Yoshida Noro, and C. Wylie. 1994. Overexpression of cadherins and underexpression of $\beta$-Catenin inhibit dorsal mesoderm induction in early Xenopus embryos. Cell 79: 791-803.

Hemmanti-Brivanlou, A. and D.A. Melton. 1992. A truncated activin receptor inhibits mesoderm induction and formation of axial structures in Xenopus embryos. Nature 359: 609614.

Herrmann, B.G. 1991. Expression pattern of the Brachyury gene in whole-mount $\mathrm{T}^{\text {Wis }} / \mathrm{T}^{\text {Wis }}$ mutant embryos. Development 113: 913-917.

Izpisua-Belmonte, J.C., E.M. DeRobertis, K.G. Storey, and C.D. Stern. 1993. The homeobox gene goosecoid and the origin of the organizer cells in the early chick blastoderm. Cell 74: 645-659.

Kadonaga, J.T. and R. Tiian. 1986. Affinity purification of sequence-specific DNA binding proteins. Proc. Natl. Acad. Sci. 83: 5889-5893.

Kimelman, D., J.L. Christian, and R.T. Moon. 1992. Synergistic principles of development: Overlapping patterning systems in Xenopus mesoderm induction. Development 116: 1-9.

$\mathrm{Ku}, \mathrm{M}$. and D.A. Melton. 1993. Xwnt-11 - A maternally expressed Xenopus Wnt gene. Development 119: 1161-1173.

Labonne, C. and M. Whitman. 1994. Mesoderm induction by activin requires FGF-mediated intracellular signals. Development 120: 463-472.

Lemaire, P., N. Garrett, and J.B. Gurdon. 1995. Expression cloning of Siamois, a Xenopus homeobox gene expressed in dorsal vegetal cells of blastulae and able to induce a complete secondary axis. Cell 81: 85-94.

Luckow, B. and G. Schutz. 1987. CAT constructions with multiple unique restriction sites for the functional analysis of eukaryotic promoters and regulatory elements. Nucleic Acids Res. 15: 5490.

Maniatis, T., E.F. Fritsch, and J. Sambrook. 1982. Molecular cloning: A laboratory manual. Cold Spring Harbor Laboratory, Cold Spring Harbor, New York.

Matzuk, M.M., T.R. Kumar, A. Vassalli, J.R. Bickenbach, D.R. Roop, R. Jaenisch, and A. Bradley. 1995a. Functional analysis of activins during mammalian development. Nature 374: 354-356.

Matzuk, M.M., T.R. Kumar, and A. Bradley. 1995b. Different phenotypes for mice deficient in either activins or activin receptor type-II. Nature 374: 356-360.

Moon, R.T. and J.L. Christian. 1992. Competence modifiers synergize with growth factors during mesoderm induction and patterning in Xenopus. Cell 71: 709-712.

Moon, R.T., R.M. Campbell, J.L. Christian, L.L. McGrew, I. Shih, and S. Fraser. 1993. Xwnt-5A: A maternal Wnt that affects morphogenetic movements after overexpression in embryos of Xenopus laevis. Development 119: 97-111.

Niehrs, C., R. Keller, K.W.Y. Cho, and E.M. DeRobertis. 1993. The homeo box gene goosecoid controls cell migration in Xenopus embryo. Cell 72: 491-503.

Nieuwkoop, P.D. 1969. The formation of the mesoderm in urodelan amphibians. I. Induction by the endoderm Wilhelm Roux's Arch. Entwicklungsmech. 162: 341-373.

1973. The organization center of the amphibian embryo: 
Its origin, spatial organization, and morphogenetic action. Adv. Morphol. 10: 1-39.

Nieuwkoop, P.D. and I. Faber. 1967. A normal table of Xenopus laevis (Daudin). North Holland Publishing Co., Amsterdam, The Netherlands.

Rosa, F.M. 1989. Mix.1, a homeo box mRNA inducible by mesoderm inducers, is expressed mostly in the presumptive endodermal cells of Xenopus embryos. Cell 57: 965-974.

Rothbächer, U., M.N. Laurent, I.L. Blitz, T. Watabe, J.L. Marsh, and K.W.Y. Cho. 1995. Functional conservation of the Wnt signaling pathway revealed by ectopic expression of Drosophila dishevelled in Xenopus. Dev. Biol. 170: 717-721.

Schmidt, J.E., A. Suzuki, N. Ueno, and D. Kimelman. 1995. Localized BMP-4 mediates dorsal/ventral patterning in the early Xenopus embryo. Dev. Biol. 169: 37-50.

Schulte-Merker, S., R.K. Ho, B.G. Herrmann, and C. NüssleinVolhard. 1992. The protein product of the zebrafish homologue of the mouse $T$ gene is expressed in nuclei of the germ ring and the notochord of the early embryo. Development 116: $1021-1032$.

Smith, J.C. 1993. Mesoderm-inducing factors in early vertebrate development. EMBO I. 12: 4463-4470.

Smith, J.C., B.M. Price, J.B. Green, D. Weigel, and B.G. Herrmann. 1991. Expression of a Xenopus homolog of Brachyury $(T)$ is an immediate-early response to mesoderm induction. Cell 67: 79-87.

Smith, W.C. and R.M. Harland. 1991. Injected Xwnt-8 RNA acts early in Xenopus embryos to promote formation of a vegetal dorsalizing factor. Cell 67: 829-840.

- 1992. Expression cloning of noggin, a new dorsalizing factor localized to the Spemann organizer in Xenopus embryos. Cell 70: 829-840.

Smith, W.C., R. McKendry, S. Ribisi Jr., and R.M. Harland. 1995. A nodal-related gene defines a physical and functional domain within the Spemann organizer. Cell 82: 37-46.

Sokol, S. and D.A. Melton. 1992. Interaction of Wnt and activin in dorsal mesoderm induction in Xenopus. Dev. Biol. 154: $348-355$

Sokol, S., J.L. Christian, R.T. Moon, and D.A. Melton. 1991 Injected Wnt-8 RNA induces a completed body axis in $X e$ nopus embryos. Cell 67: 741-752.

Spemann, H. and H. Mangold. 1924. Über induktion von em. bryonalanlagen durch implantation artfremder organisatoren. Wilhelm Roux's Arch. Dev. Biol. 100: 599-638.

Stachel, S.E., D.J. Grunwald, and P.J. Myers. 1993. Lithium pertubation and goosecoid expression identify a dorsal specification pathway in the pregastula zebrafish. Development 117: 1261-1274

Suzuki, A., R.S. Thies, N. Yamaji, J.J. Song, J.M. Wozney, K Murakami, and N. Ueno. 1994. A truncated bone morphogenetic protein receptor affects dorsal-ventral patterning in the early Xenopus embryo. Proc. Natl. Acad. Sci.91: 1025510259.

Taira, M., M. Jamrich, P.J. Good, and I.B. Dawid. 1992. The LIM domain-containing homeo box gene Xlim-1 is expressed specifically in the organizer region of Xenopus gastrula embryos. Genes \& Dev. 6: 356-366.

Tannahill, D. and D.A. Melton. 1989. Localized synthesis of the $\mathrm{Vg} 1$ protein during early Xenopus development. Development 106: 775-785.

Thomsen, G. and D.A. Melton. 1993. Processed Vg-1 protein is an axial mesoderm inducer in Xenopus. Cell 74: 433-441.

Thomsen, G., T. Woolf, M. Whitman, S. Sokol, J. Vaughan, W. Vale, and D.A. Melton. 1990. Activins are expressed early in Xenopus embryogenesis and can induce axial mesoderm and anterior structures. Cell 63: 485-493. von Baer, K.E. 1828. Entwicklungsgeschichte der Tiere: Beobachtung und Reflexionen. Börntraager, Königsberg, Germany. 


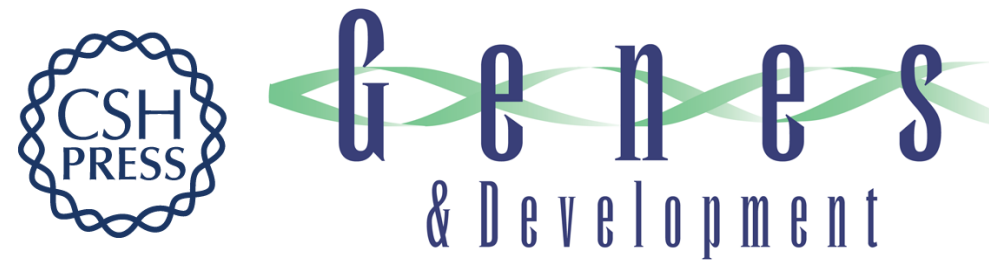

\section{Molecular mechanisms of Spemann's organizer formation: conserved growth factor synergy between Xenopus and mouse.}

T Watabe, S Kim, A Candia, et al.

Genes Dev. 1995, 9:

Access the most recent version at doi:10.1101/gad.9.24.3038

References This article cites 52 articles, 18 of which can be accessed free at:

http://genesdev.cshlp.org/content/9/24/3038.full.html\#ref-list-1

License

Email Alerting

Service

Receive free email alerts when new articles cite this article - sign up in the box at the top right corner of the article or click here.

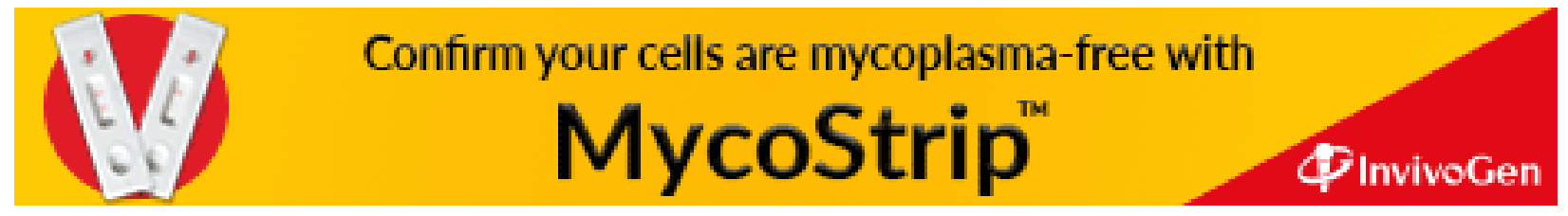

